\title{
Toby Garfitt, Claude Herly (ed.), L'enfance inspiratrice. Eclats et blessures
}

\section{Elisa Bricco}

\section{Q OpenEdition}

1 Journals

\section{Edizione digitale}

URL: http://journals.openedition.org/studifrancesi/30792

DOI: 10.4000/studifrancesi.30792

ISSN: 2421-5856

\section{Editore}

Rosenberg \& Sellier

\section{Edizione cartacea}

Data di pubblicazione: 1 avril 2006

Paginazione: 193

ISSN: 0039-2944

\section{Notizia bibliografica digitale}

Elisa Bricco, «Toby Garfitt, Claude Herly (ed.), L'enfance inspiratrice. Eclats et blessures», Studi Francesi

[Online], 148 (XLX | I) | 2006, online dal 30 novembre 2015, consultato il 21 avril 2021. URL: http:// journals.openedition.org/studifrancesi/30792 ; DOI: https://doi.org/10.4000/studifrancesi.30792

Questo documento è stato generato automaticamente il 21 avril 2021.

\section{(c) $(1) \&$}

Studi Francesi è distribuita con Licenza Creative Commons Attribuzione - Non commerciale - Non opere derivate 4.0 Internazionale. 


\title{
Toby Garfitt, Claude Herly (ed.), L'enfance inspiratrice. Eclats et blessures
}

\author{
Elisa Bricco
}

\section{NOTIZIA}

TOBY GARFITT, CLAUDE HERLY (ed.), L'enfance inspiratrice. Eclats et blessures, Paris,

L'harmattan, 2004, pp. 267.

1 Gli atti del convegno sull'Enfance inspiratrice che si è tenuto a Parigi nel giugno 2004, contengono studi interessanti su autori del XX secolo (François Mauriac, Julien Green, Saint-John Perse, Henri Bosco, Albert Camus) e alcuni saggi su romanzieri francesi contemporanei per i quali l'infanzia è stata fonte di ispirazione, punto di partenza esistenziale e creativo.

2 La seconda sezione del volume è dedicata a due autori "classici" del Novecento: Patrick Modiano e J.M.G. Le Clézio. MARIE-LINE JACQUET propone una lettura di un romanzo in Ombres et lumières de l'enfance dans "La Petite Bijou" de Patrick Modiano, pp. 73-83; mentre DANIÈLE HENKY traccia un percorso nella scrittura di Le Clézio mettendo in luce il ruolo fondatore dell'infanzia in tutti i suoi romanzi per ragazzi: momento magico di assoluta apertura incondizionata verso il mondo e l'esperienza, al quale gli adulti dovrebbero ispirarsi (J.M.G. Le Clézio: "Je suis né dans mon enfance" ou la quête orientée, pp. 57-71).

Nelle sezioni seguenti si succedono gli approfondimenti, le letture e le introduzioni a autori contemporanei per i quali l'infanzia costituisce un periodo magico da cui prendere ispirazione, in cui rifugiarsi idealmente e in cui trarre l'energia per affrontare la vita adulta: Charles Juliet (MARIE AINE NI MHAINNIN, L'enfance inspiratrice chez Charles Juliet, pp. 103-116), François Cheng (MARIE-LOUISE SCHEIDAUER, Le chant originel dans "L'Eternité n'est pas de trop" de F. Cheng, pp. 153-165), Romain Gary (TARAS IVASSIUTINE, L'enfance inspiratrice chez Romain Gary, pp. 181-193), Didier Decoin (PATRICK GROMALLY, 
Introduction à Didier Decoin, pp. 195-205), Pascal Quignard (ANNE CLANCIER, Pascal Quignard et l'enfance, pp. 207-212), Andrei Makine ( SOPHIE OLLIVIER, France et création dans "Le Testament français" de A. Makine, pp. 213-224). 